\title{
Humanin rescues cultured rat cortical neurons from NMDA-induced toxicity through the alleviation of mitochondrial dysfunction
}

This article was published in the following Dove Press journal:

Drug Design, Development and Therapy

18 April 2017

Number of times this article has been viewed

\section{Ai-Ling Cui, ' Ying-Hua Zhang, ${ }^{2}$ Jian-Zhong $\mathrm{Li}^{3}{ }^{3}$ Tianbin Song, ${ }^{4}$ Xue-Min Liu,' Hui Wang, ${ }^{2}$ Ce Zhang, ${ }^{5}$ Guo-Lin Ma, ${ }^{6}$ Hui Zhang, ${ }^{7}$ Kefeng $\mathrm{Li}^{8}$}

'Anatomy Department, Changzhi Medical College, Changzhi, Shanxi, ${ }^{2}$ Key Laboratory of Tissue Regeneration of Henan Province, Xinxiang Medical University, Xinxiang, Henan, ${ }^{3}$ Clinical Laboratory of Heji Hospital Affiliated to Changzhi Medical College, Changzhi, Shanxi, ${ }^{4}$ Department of Nuclear Medicine, Xuanwu Hospital, Capital Medical University, Beijing, ${ }^{5}$ Department of Physiology, Shanxi Medical University, Taiyuan, Shanxi, ' ${ }^{6}$ Department of Radiology, China-Japan Friendship Hospital, Beijing, 'Department of Radiology, First Clinical Medical College, Shanxi Medical University, Taiyuan, Shanxi, People's Republic of China; ${ }^{8}$ School of Medicine, University of California - San Diego, San Diego, CA, USA

Correspondence: Guo-Lin Ma Department of Radiology, China-Japan Friendship Hospital, No. 2 Yinghua Dongjie, Chaoyang District, Beijing, 100029, People's Republic of China Email maguolinI007@qq.com

Ying-Hua Zhang

Key Laboratory of Tissue Regeneration of Henan Province, Xinxiang Medical University, East Jinsui Road, Xinxiang, Henan 453003, People's Republic of China

Email 125642685@qq.com

\begin{abstract}
N$-methyl-D-aspartate (NDMA) receptor-mediated excitotoxicity has been implicated in a variety of pathological situations such as Alzheimer's disease (AD) and Parkinson's disease. However, no effective treatments for the same have been developed so far. Humanin (HN) is a 24-amino acid peptide originally cloned from the brain of patients with $\mathrm{AD}$ and it prevents stress-induced cell death in many cells/tissues. In our previous study, HN was found to effectively rescue rat cortical neurons. It is still not clear whether HN protects the neurons through the attenuation of mitochondrial dysfunction. In this study, excitatory toxicity was induced by NMDA, which binds the NMDA receptor in primarily cultured rat cortical neurons. We found that NMDA $(100 \mu \mathrm{mol} / \mathrm{L})$ dramatically induced the decrease of cell viability and caused mitochondrial dysfunction. Pretreatment of the neurons with HN $(1 \mu \mathrm{mol} / \mathrm{L})$ led to significant increases of mitochondrial succinate dehydrogenase (SDH) activity and membrane potential. In addition, $\mathrm{HN}$ pretreatment significantly reduced the excessive production of both reactive oxygen species (ROS) and nitric oxide (NO). Thus, HN could attenuate the excitotoxicity caused by the overactivation of the NMDA receptor through the alleviation of mitochondrial dysfunction.
\end{abstract}

Keywords: NMDA-induced toxicity, mitochondrial dysfunction, humanin, alleviation

\section{Introduction}

Glutamate is an essential excitatory neurotransmitter in the central nervous system (CNS). Its accumulation in the synaptic cleft, however, triggers the excessive activation of the $N$-methyl-D-aspartate (NMDA) receptor and, consequently, the influx of extracellular calcium. ${ }^{1-3}$ The fine spatial and temporal organization of intracellular calcium signals is fundamental to the functions of the CNS, perhaps more than for any other tissues. ${ }^{4}$ Calcium signals are conveyed throughout the CNS by local changes in the calcium concentration $\left(\left[\mathrm{Ca}^{2+}\right]_{\mathrm{c}}\right)$. The rapid increase of $\left(\left[\mathrm{Ca}^{2+}\right]_{\mathrm{c}}\right)$ in the cytoplasm activates $\mathrm{Ca}^{2+}$ channels on the mitochondrial membrane and triggers calcium flux into the mitochondrial matrix. In the matrix, calcium upregulates the activity of $\mathrm{Ca}^{2+}$-sensitive dehydrogenases of the Krebs cycle and the $\mathrm{F}_{1} \mathrm{~F}_{0}$-ATP synthase and thereby controls the rate of ATP production. ${ }^{5,6}$ A pathological aspect of this process is linked with the mitochondrial $\mathrm{Ca}^{2+}$ overload, which might trigger the activation of the mitochondrial permeability transmission pore, which in turn releases apoptotic and necrotic signal factors, leading to cell death. ${ }^{7,8}$ Neuronal energy supplies are, meanwhile, entirely based on mitochondrial oxidative phosphorylation, making them especially vulnerable to mitochondrial dysfunction. ${ }^{4}$ 
Because the overactivation of the NMDA receptor is the pivotal factor in the damage process, NMDA receptor antagonists have been explored for many years as therapeutic agents for the treatment of excitatory neurotoxicity-oriented neurological disorders, such as stroke, epilepsy, pain, and Parkinson's disease. However, it has been discovered that many of these compounds can cause adverse behavioral effects and produce neurotoxicity. ${ }^{9,10}$

Humanin $(\mathrm{HN})$ is a 24 -amino acid peptide located in the mitochondria and cloned in 2001 from the occipital lobe of patients with Alzheimer's disease (AD) during autopsy. ${ }^{11,12}$ It was considered an $\mathrm{AD}$-selective neuroprotective peptide at the very beginning. ${ }^{13}$ Later, however, several $\mathrm{HN}$ homologs have been discovered in other species of animals, including rat, mouse, monkey, and nematode ${ }^{11,14}$ and identified in other tissues apart from the brain, including testes, colon, skeletal muscles, and human vascular walls. ${ }^{14-17} \mathrm{HN}$ 's widespread distribution implies that its role is versatile, not restricted to just attenuating AD-related insults.

In our previous study, $\mathrm{HN}$ was used to attenuate NMDAinduced neurotoxicity. ${ }^{18}$ The results showed that HN could effectively rescue cultured rat cortical neurons. However, $\mathrm{HN}$ did not block the intracellular $\mathrm{Ca}^{2+}$ overload triggered by NMDA. It might induce the reverting of the high $\mathrm{Ca}^{2+}$ concentration quickly. ${ }^{18}$ It is still not clear whether $\mathrm{HN}$ protects the neurons through attenuation of NMDA-induced mitochondrial dysfunction.

\section{Materials and methods Primary cerebral cortical neuronal culture}

The study protocol was reviewed and approved by the institutional review board (IRB) of the Changzhi Medical College, People's Republic of China (IRB number 2015021453) in accordance with the guidance for the care and use of laboratory animals, issued by the Ministry of Science and Technology of China. The primarily cultured cortical neurons were prepared using neonatal Wistar rats (P1-3). Briefly, the pups were decapitated and the cerebral cortices were isolated and immersed into ice-cold D-Hanks buffer containing $\mathrm{NaCl}$ $136.7 \mathrm{mM}, \mathrm{KCl} 5.4 \mathrm{mM}, \mathrm{NaHCO}_{3} 4.2 \mathrm{mM}, \mathrm{KH}_{2} \mathrm{PO}_{4} 0.4 \mathrm{mM}$, $\mathrm{NaH}_{2} \mathrm{PO}_{4} 0.6 \mathrm{mM}$, and glucose $5.6 \mathrm{mM}$, with $\mathrm{pH}=7.4$. To dissociate the cortices into single cells, they were minced mechanically into grains of $\sim 1 \mathrm{~mm}^{3}$. The minced cortices were then digested with trypsin $\left(0.03 \%, \mathrm{pH} 7.4,37^{\circ} \mathrm{C}\right.$, Sigma $)$ for $1 \mathrm{~min}$, centrifuged at 2,500 rpm for $5 \mathrm{~min}$, and then resuspended in Dulbecco's Modified Eagle's Medium (DMEM) (Gibco) containing fetal calf serum (FCS, Sigma) 20\% (v/v) and penicillin-streptomycin $100 \mathrm{U} / \mathrm{mL}$. Cortical cells were plated on poly-D-lysine-coated 6-well $(3 \mathrm{~mL})$ or 96 -well $(100 \mu \mathrm{L})$ plates (Costar) at $5 \times 10^{5}$ cells $/ \mathrm{mL}$. Cells grown on 6-well plates with coverslips were used for the visualization experiments under a confocal microscope (reactive oxygen species [ROS] and mitochondrial membrane potential). Cells grown on 6-well plates without coverslips were used for the quantification of ROS by flow cytometry, and the medium was collected for the quantitative analysis of nitric oxide (NO) and lactate dehydrogenase (LDH) release. Cells grown on 96-well plates were used for the measurement of succinate dehydrogenase (SDH) activity. Cytosine arabinoside (Ara-C) (Sigma) $(10 \mu \mathrm{mol} / \mathrm{L})$ was added $24 \mathrm{~h}$ after cell plating to limit the proliferation of nonneuronal cells. The culture media were half-refreshed every 2 days. All experiments were performed on 9th day in vitro (DIV9).

\section{Experimental groups and chemical treatments}

In this study, the cultured neurons were grouped as follows: 1) control group, containing cultured neurons only; 2) $\mathrm{HN}$ group, containing cultured neurons incubated with $\mathrm{HN}$ ( $1 \mu \mathrm{mol} / \mathrm{L}$; Shanghai Shenggong Co. Ltd., Shanghai, People's Republic of China); 3) NMDA group, containing cultured neurons incubated with NMDA $(100 \mu \mathrm{mol} / \mathrm{L}$; Sigma Aldrich Co., St Louis, MO, USA) and glycine $(10 \mu \mathrm{mol} / \mathrm{L}$; Sigma Aldrich Co.) for $2.5 \mathrm{~h}$; 4) NMDA + MK-801 group, wherein MK-801 (10 $\mu \mathrm{mol} / \mathrm{L}$; Sigma Aldrich Co.) was added to the NMDA treatment; 5) NMDA + HN group, in which $\mathrm{HN}(1 \mu \mathrm{mol} / \mathrm{L})$ was added to NMDA treatment; 6$)$ $\mathrm{NMDA}+\mathrm{S} 7 \mathrm{~A}-\mathrm{HN}$ (inactive form of HN; $1 \mu \mathrm{mol} / \mathrm{L}$; Beijing SBS Genetech, Beijing, People's Republic of China), in which S7A-HN was added along with NMDA; 7) NMDA + AGA-HNG $(100 \times$ more active form; $1 \mu \mathrm{mol} / \mathrm{L}$; Beijing SBS Genetech), with AGA-HNG being added to NMDA-treated cells. Cortical neurons isolated from the pups were cultured for 8 days before chemical treatment. $\mathrm{HN}$ was administered $16 \mathrm{~h}$ before NMDA treatment. The cultured neurons were preincubated with or without $\mathrm{HN}$, and neurotoxicity was induced by treatment with NMDA, as described previously. ${ }^{19}$ Acute neurotoxic exposure (NMDA challenge) was achieved by removing the culture medium from the cultured neurons. The collected medium was filter-sterilized and stored for future analysis. To remove traces of growth medium, cells were washed 3 times with prewarmed Locke's buffer containing (in millimoles per liter) $\mathrm{NaCl} \mathrm{154,} \mathrm{KCl} 5.6, \mathrm{NaHCO}_{3} 3.6$, $\mathrm{CaCl}_{2} 2.3, \mathrm{MgCl}_{2}$ 1.2, glucose 5.6, and 4-(2-hydroxyethyl)1-piperazine ethanesulfonic acid (HEPES) 5.0, with $\mathrm{pH}$ 7.4. 
The cells were then incubated for $2.5 \mathrm{~h}$ with either drug-free or neurotoxin-containing $\mathrm{Mg}^{2+}$-free Locke's buffer. NMDA and $\mathrm{MK}-801 / \mathrm{HN}$ were added at the concentrations mentioned earlier. The incubation was terminated by the removal of the drug-containing buffer, followed by washing with prewarmed drug-free Locke's buffer ( $\left.1 \mathrm{mmol} / \mathrm{L} \mathrm{Mg}^{2+}\right)$. Cells were harvested for analysis after $24 \mathrm{~h}$ of incubation.

\section{Quantification of LDH release}

Cell damage was estimated by measuring the activity of $\mathrm{LDH}$ in the culture medium after release from the damaged cells. In the experiment, the culture medium was collected at $24 \mathrm{~h}$ after NMDA exposure. The activity of LDH was measured as described by Koh and Choi. ${ }^{20}$ The values were expressed as the percentage compared to the control group, which was set as $100 \%$. The data presented were mean \pm standard deviation (SD) for 5 independent experiments using different batches of cells.

\section{Dimethylthiazolyldiphenyl tetrazolium bromide (MTT) assay for cell viability}

The cell viability was evaluated using a cell proliferation kit (MTT assay; Sigma-Aldrich, St Louis, MO, USA) according to the manufacturer's protocol. Briefly, the cells were incubated with MTT for $4 \mathrm{~h}$ at $37^{\circ} \mathrm{C}$. After incubation, dimethyl sulfoxide was added to lyse the cells and dissolve the formazan crystals. The absorbance was recorded at $490 \mathrm{~nm}$ using a microplate reader (iMark, Bio-Rad). Cell viability was expressed as the percentage of absorption relative to the control group, which was exposed to drug-free buffer (set as 100\%).

\section{SDH activity measurement}

The SDH activity was measured using an SDH activity colorimetric assay kit (Biovision, Milpitas, CA, USA), which was performed $24 \mathrm{~h}$ after NMDA treatment, as described earlier. ${ }^{21}$ The absorbance was recorded at $600 \mathrm{~nm}$ in kinetic mode for 10-30 min in a microplate reader (Benchmark, Bio-Rad). The activity of SDH was expressed as the percentage of the absorption in the control group, which was exposed to drugfree buffer (and set as 100\%).

\section{Measurement of intracellular $\mathrm{Ca}^{2+}$ concentration}

On DIV8, the cultured neurons on coverslips were treated with HN. After $16 \mathrm{~h}$, all groups were washed 3 times in Locke's buffer. They were then treated with $5 \mu \mathrm{mol} / \mathrm{L}$ of Fluo 3-AM (calcium inhibitor) (Biotium, Fremont, CA, USA) in the dark and incubated at $37^{\circ} \mathrm{C}$ for $40 \mathrm{~min}$. The neurons were then washed 3 times with D-Hanks buffer and visualized under a confocal microscope (TCS SP5 II; Leica). $\mathrm{Ca}^{2+}$-dependent fluorescence intensity was measured at an excitation wavelength of $488 \mathrm{~nm}$ and an emission wavelength of $530 \mathrm{~nm}$. Dynamic changes in the levels of cytoplasmic $\mathrm{Ca}^{2+}$ were captured and recorded every $660 \mathrm{~ms}$ for total 300 successive measurements ( $198 \mathrm{~s})$ for each neuron. Further, 5-10 neurons were measured in each group, and the average intensity represented the intracellular instantaneous $\mathrm{Ca}^{2+}$ concentration of each group.

\section{Detection of cellular mitochondrial membrane potential $(\Delta \Psi \mathrm{m})$}

The mitochondrial membrane potential $(\Delta \Psi m)$ was measured by staining the cells with $\mathrm{JC}-1\left(5,5^{\prime}, 6,6^{\prime}\right.$-tetrachloro- $1,1^{\prime}, 3,3^{\prime}$-te traethylbenzimidazolylcarbocyanine iodide) fluorescent probe. JC-1 was added into the serum-free DMEM (final concentration: $5 \mu \mathrm{g} / \mathrm{mL}$ ) and incubated at $37^{\circ} \mathrm{C}$ for $30 \mathrm{~min}$ in the dark. After washing 3 times with phosphate-buffered saline (PBS) $(0.01 \mathrm{~mol} / \mathrm{L}, \mathrm{pH} 7.4)$, the neurons with the coverslips were fixed in freshly prepared paraformaldehyde at $4^{\circ} \mathrm{C}$ for $30 \mathrm{~min}$. The JC-1 polymer was then washed 3 times with $\mathrm{PBS}(0.01 \mathrm{~mol} / \mathrm{L}$, $\mathrm{pH}$ 7.4) again, and the red fluorescence was visualized under a confocal laser scanning microscope. The neurons on plates without coverslips were digested with trypsin-EDTA (trypsin $0.027 \%$, EDTA $0.025 \%$; pH 7.4) and collected in $500 \mu \mathrm{L} \mathrm{PBS}$ at the cell concentration of $>1 \times 10^{6} / \mathrm{mL}$. The cell fluorescence intensity was measured using a fluorescence-activated cell sorting (FACS) flow cytometer (Becton Dickinson, Franklin Lakes, NJ, USA). The maximum excitation wavelength of $\mathrm{JC}-1$ polymer (J-aggregates) was $530 \mathrm{~nm}$, and the maximum emission wavelength was $590 \mathrm{~nm}$.

\section{Measurement of intracellular ROS}

To measure the intracellular accumulation of ROS, a fluorometric assay using intracellular oxidation of dichlorodihydrofluorescein diacetate (DCFH-DA) was performed. Briefly, the cultured cortical neurons were washed twice with serum-free DMEM. DCFH-DA was added to the medium (final concentration: $10 \mu \mathrm{mol} / \mathrm{L}$ ) and incubated with the neurons in the dark for $40 \mathrm{~min}$. The neurons were then washed 3 times with Locke's buffer and treated with NMDA to induce cytotoxicity as described. After washing twice with PBS (0.01 M, pH 7.4), the neurons on the coverslips were fixed in freshly prepared paraformaldehyde at $4^{\circ} \mathrm{C}$ for $30 \mathrm{~min}$. The fluorescent dichlorofluorescein (DCF) was visualized by a confocal microscope. The neurons on the plates without coverslips were digested with trypsin-EDTA 
(trypsin $0.027 \%$, EDTA $0.025 \%$; pH 7.4) and collected in $500 \mu \mathrm{L}$ of PBS at a cell concentration of $1 \times 10^{6} / \mathrm{mL}$ for testing by flow cytometry. The cells' fluorescence intensity was measured using the flow cytometer (Becton Dickinson, USA) at $490 \mathrm{~nm}$ excitation and $530 \mathrm{~nm}$ emission.

\section{NO determination}

NO was determined by the colorimetric method using a commercial kit (Nanjing Jiangcheng Biological Engineering Company, People's Republic of China). Briefly, after NMDA treatment, the cultured cortical neurons were collected, and NO concentration was measured according to the manufacturer's protocol.

\section{Protein extraction and Western blot analysis}

Mitochondrial-enriched proteins were isolated with a Mitochondrial/Cytosolic Fractionation kit (Abcam, Cambridge, MA, USA) according to the manufacturer's protocol. Briefly, the cells were harvested and lysed with cytosol extraction buffer mix. The homogenized cells were then centrifuged at $16,000 \times \mathrm{g}$ for $10 \mathrm{~min}$ at $4^{\circ} \mathrm{C}$. The pellet contained the intact mitochondria. The pellet was then resuspended in mitochondrial extraction buffer mix containing dithiothreitol (DTT) and protease inhibitors. Protein concentration was determined using Pierce bicinchoninic acid protein assay (Pierce Chemicals). Twenty micrograms of protein was treated with $1 \times$ reducing agent (Life Technologies) in $1 \times$ LDS buffer (Life Technologies), heated for $10 \mathrm{~min}$ at $95^{\circ} \mathrm{C}$, loaded onto a $10 \%$ bis-Tris polyacrylamide gel, and electrophoresed at $150 \mathrm{~V}$ for $1.5 \mathrm{~h}$. Proteins were transferred to nitrocellulose, followed by blocking with $3 \%$ milk for $1 \mathrm{~h}$. The filter was washed with $1 \times$ Tris-buffered saline containing Tween-20 (TBST) and probed with the primary antibody anti-mitochondrial succinate dehydrogenase subunit B (SDHB) (Abcam, 1:1,000 dilution) or anti-inducible nitric oxide synthase (iNOS) (Abcam, 1:2,000 dilution) overnight. A monoclonal antibody raised against the structural protein beta-actin (1:1,000 dilution, Sigma) was used as the control. Horseradish peroxidase-conjugated anti-rabbit/mouse secondary antibody (GE Healthcare, Wauwatosa, WI, USA, 1:15,000) and an ECL plus kit (Pierce, Waltham, MA, USA) were used to detect the protein. The intensity of the bands was analyzed using ImageJ 1.3.8. Fold change (experimental group/control) was calculated and plotted.

\section{Statistical analysis}

All data were expressed as mean \pm SD $(n=5)$. The significance of the difference between groups was tested using 1-way analysis of variance (ANOVA), followed by Tukey's multiple-comparisons test; $P$-values $<0.05$ were considered statistically significant.

\section{Results \\ NMDA induced leakage of LDH from cultured rat cortical neurons in a dose- dependent manner}

As shown in Figure 1, NMDA treatment resulted in the leakage of LDH from the neurons in a dose-dependent manner. NMDA is an excitotoxin that induces the overactivation of the NMDA receptor and causes excitotoxicity. Compared with the control group, the LDH activity was significantly increased by $39.3 \%$ and $70.7 \%$, respectively, in the 2 NMDA treatment groups (50 and $100 \mu \mathrm{mol} / \mathrm{L})$, and the neurons were dramatically damaged. MK-801 is an uncompetitive channel blocker of the NMDA receptor. MK-801 inhibited the increase of $\mathrm{LDH}$ release, suggesting that the increase of LDH release was triggered by NMDA.

\section{$\mathrm{HN}$ caused dose-dependent restoration of the NMDA-triggered cell viability reduction in cultured rat cortical neurons}

NMDA exposure $(100 \mu \mathrm{mol} / \mathrm{L})$ induced the damage of neuron cells and caused a decrease of cell viability to levels $\sim 53.2 \%$ of the controls, as shown in Figure 2. The cell viability was significantly increased by the addition of $\mathrm{HN}$ in a dose-dependent manner. When the concentration of

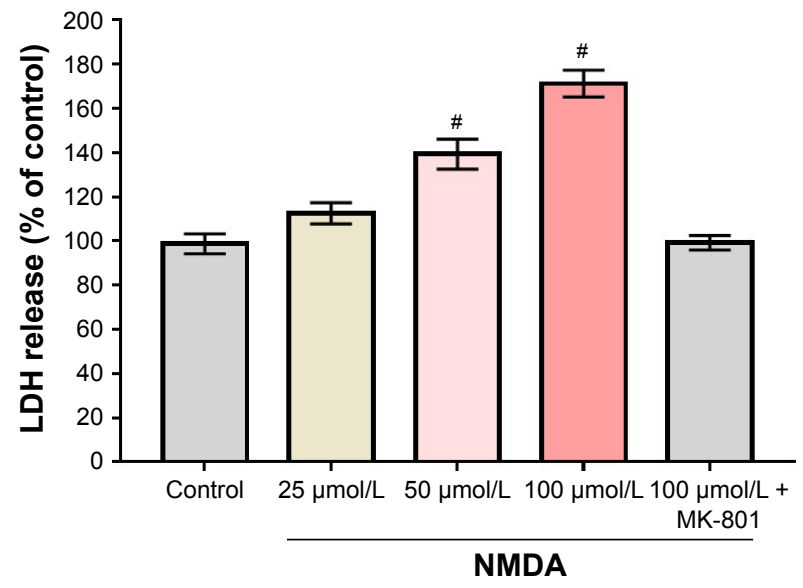

Figure I LDH leakage induced by NMDA in cultured rat cortical neurons. Notes: Data are expressed as the percentages of the mean values of the control group $(100 \%)$ and are represented as mean \pm SD $(n=5)$. One-way ANOVA followed by post hoc Tukey's test was performed for statistical analysis. "NMDA group versus control group, $P<0.05$. Control group versus NMDA + MK-80I group, $P=0.995$; control versus NMDA ( $25 \mu \mathrm{mol} / \mathrm{L}), P=0.08 \mathrm{I}$; control versus NMDA $(50 \mu \mathrm{mol} / \mathrm{L})$, $P=0.000$; control versus NMDA ( $100 \mu \mathrm{mol} / \mathrm{L}), P=0.00 \mathrm{I}$. MK- $80 \mathrm{I}$ : $10 \mu \mathrm{mol} / \mathrm{L}$.

Abbreviations: ANOVA, analysis of variance; $\mathrm{LDH}$, lactate dehydrogenase; NMDA, N-methyl-D-aspartate; SD, standard deviation. 


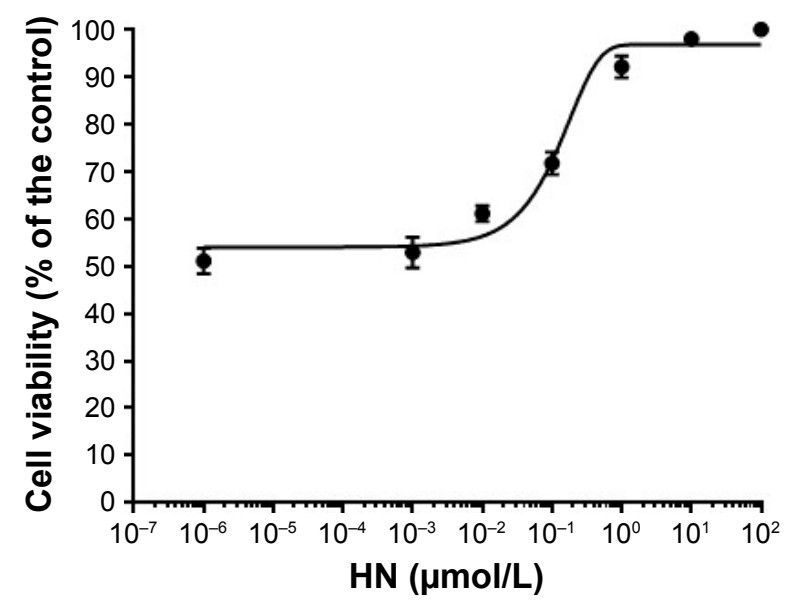

Figure 2 The effect of $\mathrm{HN}$ on NMDA-induced cell viability reduction of rat cortical neurons.

Notes: Rat cortical neurons were treated with NMDA (100 $\mu \mathrm{mol} / \mathrm{L})$. HN was added at concentrations of $0,0.00 \mathrm{I}, 0.0 \mathrm{I}, 0 . \mathrm{I}, \mathrm{I}, \mathrm{I} 0$, and $100 \mu \mathrm{mol} / \mathrm{L}$. Cell viability was measured using the MTT assay. Each point indicates the average of 5 wells from 2 separate experiments. In order to show the point of " 0 " on a log curve, we plotted " 0 " using a very small number, namely, $10^{-6}$. Data are expressed as the percentage of cell viability of the control (mean $\pm S D$ ).

Abbreviations: HN, humanin; MTT, dimethylthiazolyldiphenyl tetrazolium bromide; NMDA, N-methyl-D-aspartate; SD, standard deviation.

$\mathrm{HN}$ reached $0.1 \mu \mathrm{mol} / \mathrm{L}$, the decrease of cell viability began to be attenuated in the NMDA treatment group. When $10 \mu \mathrm{mol} / \mathrm{L}$ of $\mathrm{HN}$ was added into the medium, the viability of the neurons was $\sim 98.3 \%$ of the control group (Figure 2). Furthermore, NMDA exposure did not induce any obvious reduction in cell viability when $100 \mu \mathrm{mol} / \mathrm{L}$ of $\mathrm{HN}$ was present in the medium.

\section{HN did not block NMDA-induced intracellular increase of calcium ions}

NMDA $(100 \mu \mathrm{mol} / \mathrm{L})$ exposure induced a quick increase of cytoplasmic $\mathrm{Ca}^{2+}$ concentration, which reached its peak value within $50 \mathrm{~s}$ (Figure 3, green curve). The intracellular $\mathrm{Ca}^{2+}$ remained on the plateau during the whole observation (Figure 3, green curve). The treatment with MK-801, a blocker of the NMDA receptor, completely inhibited the increase of cytoplasmic $\mathrm{Ca}^{2+}$ triggered by NMDA (Figure 3, red curve). In contrast, $0.1 \mu \mathrm{mol} / \mathrm{L}$ of $\mathrm{HN}$ treatment did not show the inhibitory effect of NMDA-induced increase of cytoplasmic $\mathrm{Ca}^{2+}$ concentration (Figure 3, pink curve). $\mathrm{HN}$ $(1 \mu \mathrm{mol} / \mathrm{L})$ also did not block the initial sharp increase of cytoplasmic $\mathrm{Ca}^{2+}$ even though a gradual decrease of $\mathrm{Ca}^{2+}$ concentration was observed after $100 \mathrm{~s}$ (Figure 3, purple curve).

\section{$\mathrm{HN}$ attenuated the decrease of SDH activity caused by NMDA exposure}

NMDA treatment resulted in a decrease in SDH activity by $47 \%$ compared with the control group (Figure 4 ). As an

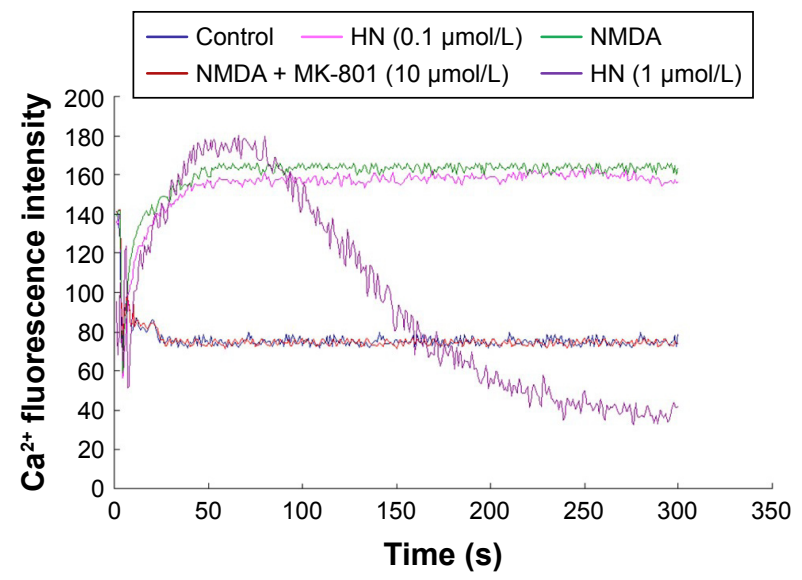

Figure 3 Effect of $\mathrm{HN}$ on NMDA-triggered dynamic changes of cytoplasmic $\mathrm{Ca}^{2+}$ concentration.

Notes: The fluorescence intensity that was correlated with the cytoplasmic $\mathrm{Ca}^{2+}$ concentration was captured and recorded every $660 \mathrm{~ms}$ for 300 successive measurements ( $198 \mathrm{~s})$ for each neuron, with 5-10 neurons being measured in every group. The curves were plotted by the connection of 300 data points that stand for the average instantaneous fluorescence intensity of each group.

Abbreviations: $\mathrm{HN}$, humanin; NMDA, $\mathrm{N}$-methyl-D-aspartate.

uncompetitive channel blocker of the NMDA receptor, MK-801 completely inhibited the decrease of SDH activity triggered by NMDA (control group against NMDA + MK-801 group, $P=0.766$ ), suggesting that the decrease of SDH activity was triggered by NMDA exposure. HN $(1 \mu \mathrm{mol} / \mathrm{L})$ did not change the activity of SDH in the control neurons. However, $\mathrm{HN}(1 \mu \mathrm{mol} / \mathrm{L})$ significantly attenuated the decrease of SDH activity triggered by NMDA $(P<0.05$ compared with the NMDA group) (Figure 4). S7A-HN is the inactive form of HN. The SDH activity in the NMDA + S7A-HN group was significantly lower than that in the control cells $(P=0.032$, control group versus NMDA + S7A-HN group), suggesting that the inactive form of $\mathrm{HN}$ did not protect against NMDA toxicity. AGA-HNG is $100 \times$ more active than the wild-type $\mathrm{HN}$. The presence of AGA-HNG significantly increased SDH activity in NMDA-treated cells $(P=0.001$, NMDA versus NMDA + AGA-HNG) (Figure 4). Western blot analysis showed that NMDA treatment significantly inhibited the expression of mitochondrial SDH subunit B (SDHB) $(P<0.05$, Figure S1A). The expression of SDHB was normalized by pretreatment with $\mathrm{HN}$ for $16 \mathrm{~h}$ prior to the addition of NMDA. HN itself did not alter SDHB expression.

\section{$\mathrm{HN}$ inhibited the decrease of mitochondrial membrane potential $(\Delta \Psi m)$ induced by NMDA exposure}

Compared to the control group, the NMDA group was darker and the average fluorescence intensity was significantly lower (Figure 5A and B). This indicated that NDMA administration 


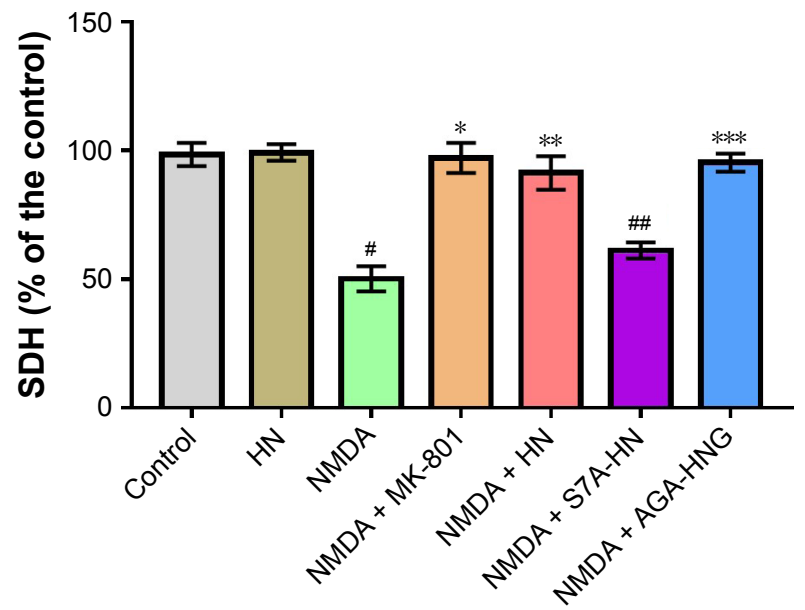

Figure 4 Effect of HN on NMDA-induced decrease of mitochondrial SDH activity. Notes: Data are expressed as mean $\pm S D(n=5)$ and are the percentage of the mean of the control group (100\%). Statistical significance was set at $P<0.05$. Data were analyzed by I-way ANOVA followed by post hoc Tukey's test for multiple comparisons. "Control group versus NMDA group, $P=0.002$; *NMDA group versus NMDA + MK-80I group, $P=0.026$; **NMDA group versus NMDA + HN group, $P=0.000 ;{ }^{\#}$ control versus NMDA + S7A-HN, P=0.032; ***NMDA versus NMDA + AGA-HNG, $P=0.001$. NMDA: $100 \mu \mathrm{M} / \mathrm{L} ; \mathrm{MK}-80 \mathrm{I}: 10 \mu \mathrm{M} / \mathrm{L} ; \mathrm{HN}, \mathrm{S} 7 \mathrm{~A}-\mathrm{HN}$, and AGA-HNG: I $\mu \mathrm{M} / \mathrm{L}$ each. NMDA is an excitotoxin that induces the overactivation of the NMDA receptor, causing excitotoxicity. MK-80I is a known uncompetitive antagonist of NMDA receptor, which could block the binding of NMDA.

Abbreviations: AGA-HNG, 100× more active form of HN; ANOVA, analysis of variance; $\mathrm{HN}$, humanin; NMDA, N-methyl-D-aspartate; S7A-HN, inactive form of $\mathrm{HN}$; SD, standard deviation; SDH, succinate dehydrogenase.

resulted in significant reduction of the membrane potential. Similarly, quantification of the membrane potential showed a $25 \%$ decrease in the NMDA-treated group compared with the control $(P=0.002)$. As an uncompetitive channel blocker of the NMDA receptor, MK-801 inhibited the reduction of the membrane potential triggered by NMDA $(P=0.026$, NMDA versus NMDA + MK-801). The fluorescence intensity of the NMDA + HN group was similar to that of the NMDA + MK-801 group (Figure 5B). The addition of $\mathrm{HN}(1 \mu \mathrm{mol} / \mathrm{L})$ could significantly attenuate the decrease of mitochondrial membrane potential triggered by NMDA $(P=0.000, \mathrm{NMDA}$ versus NMDA $+\mathrm{HN})$.

\section{$\mathrm{HN}$ reduced the production of ROS triggered by NMDA}

Although cells could be observed in a bright field, the fluorescence was weak in the control group (Figure 6A). On the contrary, the image was brighter and the cells were very clear in the NMDA group, suggesting that much more ROS had been generated compared with the control group (Figure 6A). ROS quantification revealed that the amount of ROS in the NMDA group was $\sim 20 \%$ more than that in the control group $(P=0.000$, control versus NMDA). As an uncompetitive channel blocker of the NMDA receptor, MK-801 inhibited ROS production triggered by NMDA $(P=0.000$, NMDA versus NMDA + MK-801) (Figure 6B). These results indicated that the increase of ROS production in the experiment was triggered by NMDA. The ROS level in the NMDA + HN group was similar to that of the NMDA + MK-801 group and significantly lower than that in the NMDA group $(P=0.001$, NMDA versus NMDA $+\mathrm{HN})$, suggesting that $\mathrm{HN}(1 \mu \mathrm{mol} / \mathrm{L})$ could attenuate NMDA-triggered ROS production. Similarly, we found that the inactive form
A
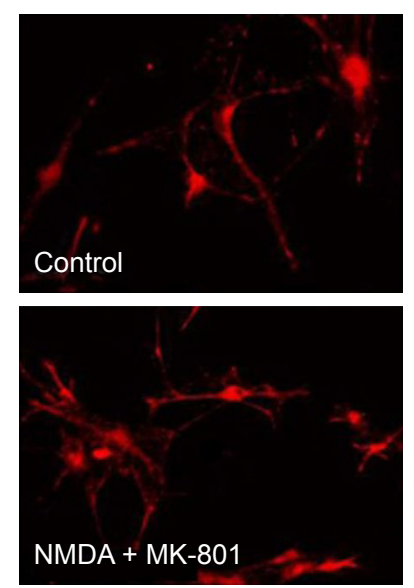
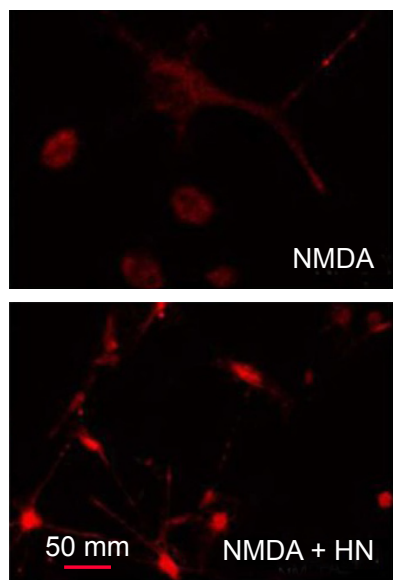

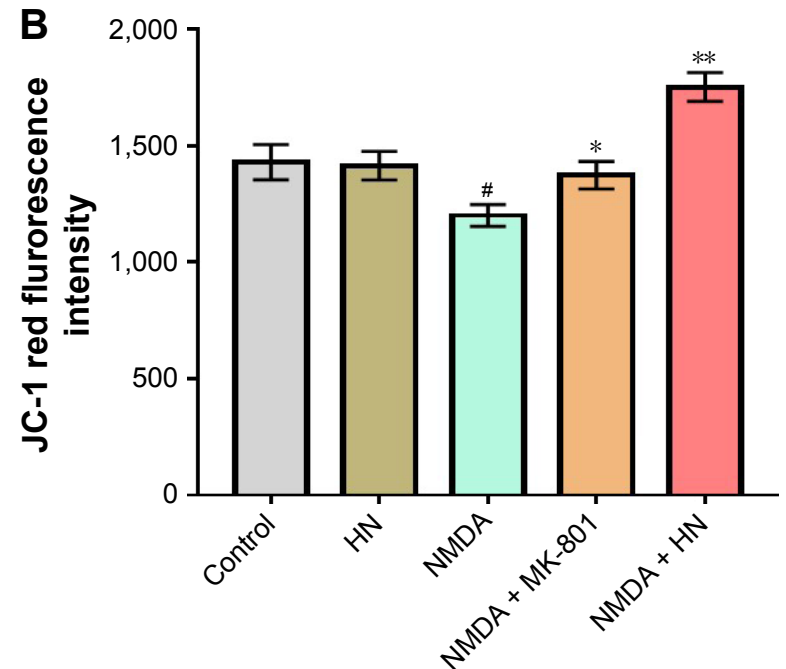

Figure 5 Effect of HN on NMDA-induced mitochondrial membrane potential reduction.

Notes: (A) Visualization of mitochondrial membrane potential in cortical neurons under a laser confocal scanning microscope $(\times 400)$. Primarily cultured cortical neurons $\left(I \times 10^{6}\right)$ were stained by JC-I on 9th day in vitro. (B) Changes of mitochondrial membrane potential in cortical neurons treated with NMDA with or without HN. Data are the mean \pm SD of 5 independent experiments. Data were analyzed by I-way ANOVA followed by post hoc Tukey's test for multiple comparisons. ${ }^{\sharp}$ Control group versus NMDA group, $P=0.002$; *NMDA group versus NMDA + MK-80I group, $P=0.026$; **NMDA group versus NMDA + HN group, $P=0.000$. NMDA: I00 $\mu$ mol/L; MK-80I: I0 $\mu$ mol/L and $\mathrm{HN}$ : I $\mu \mathrm{mol} / \mathrm{L}$. NMDA is an excitotoxin that induces the overactivation of the NMDA receptor, causing excitotoxicity. MK-80I is a known uncompetitive antagonist of NMDA receptor, which could block the binding of NMDA.

Abbreviations: ANOVA, analysis of variance; HN, humanin; NMDA, N-methyl-D-aspartate; SD, standard deviation. 
A

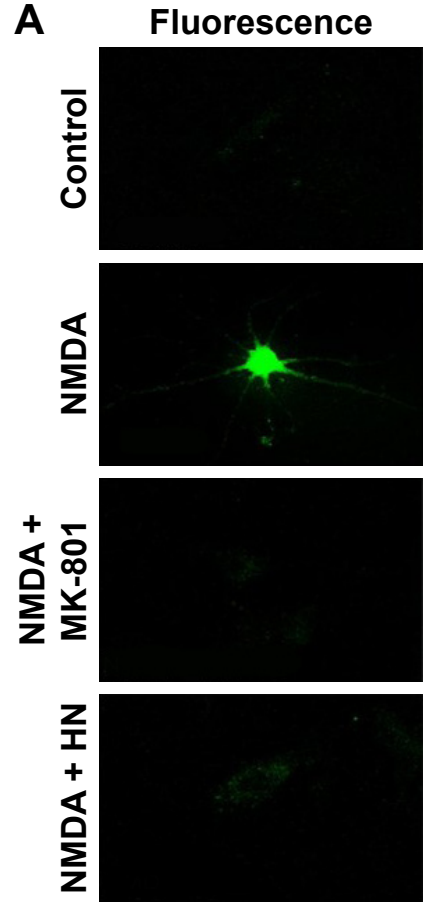

Bright field
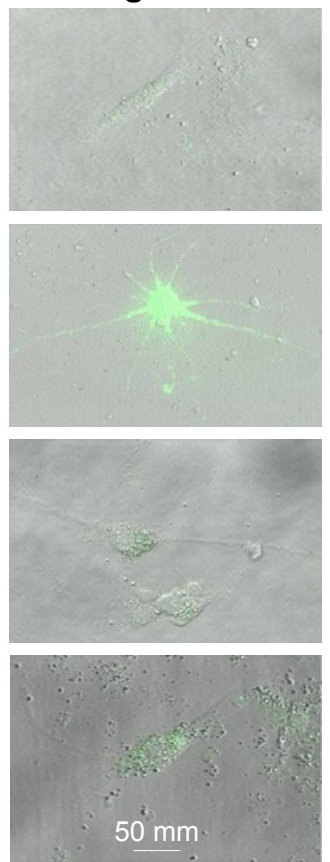

B

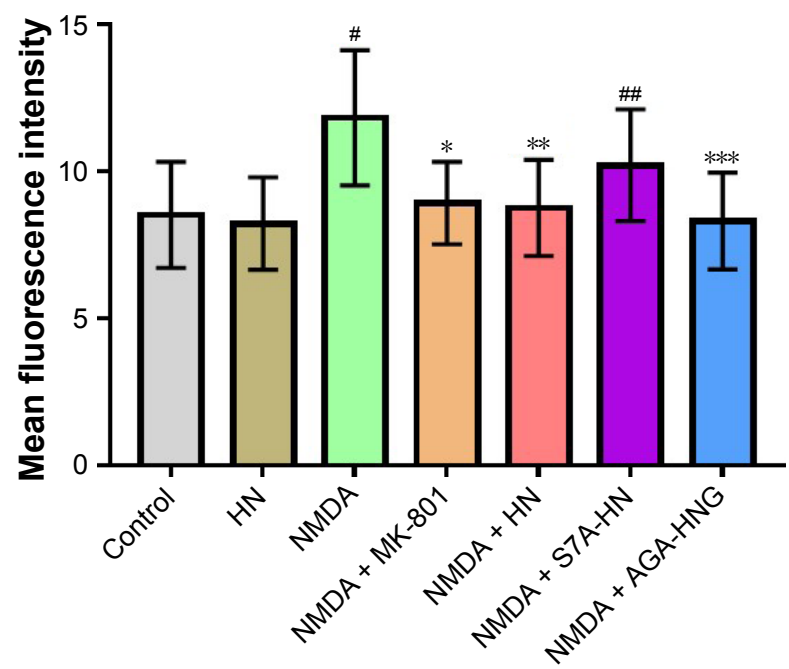

Figure 6 Effect of HN on NMDA-induced ROS production.

Notes: (A) ROS production was visualized under confocal microscope $(\times 400)$. (B) Changes in cellular ROS production in cortical neurons treated with NMDA with or without HN. A total of $1 \times 10^{6}$ cells were quantified. Data are the mean \pm SD of 5 independent observations by flow cytometry. Data were analyzed by $\mathrm{I}$-way ANOVA followed by post hoc Tukey's test for multiple comparisons. "Control group versus NMDA group, $P=0.000$, *NMDA group versus NMDA + MK-80I group, $P=0.000$; **NMDA group versus NMDA + HN group, $P=0.001$, " control versus NMDA + S7A-HN, $P=0.019 ; * * * N M D A$ versus NMDA + AGA-HNG, $P=0.022$. NMDA: I00 $\mu$ mol/L; MK-80I: $10 \mu \mathrm{mol} / \mathrm{L} ; \mathrm{HN}, \mathrm{S7A-HN}$, and AGA-HNG: I $\mu \mathrm{mol} / \mathrm{L}$ each. NMDA is an excitotoxin that induces the overactivation of the NMDA receptor, causing excitotoxicity. MK- $80 \mathrm{I}$ is a known uncompetitive antagonist of NMDA receptor, which could block the binding of NMDA.

Abbreviations: AGA-HNG, I00× more active form of HN; ANOVA, analysis of variance; HN, humanin; NMDA, N-methyl-D-aspartate; ROS, reactive oxygen species; S7A-HN, inactive form of HN; SD, standard deviation.

of HN, S7A-HN did not lower ROS production in NMDAtreated cells, while AGA-HNG $\operatorname{did}(P=0.022$, NMDA versus $\mathrm{NMDA}+\mathrm{AGA}-\mathrm{HNG})$ (Figure 6B).

\section{$\mathrm{HN}$ inhibited NMDA-triggered NO production}

As shown in Figure 7, the production of NO increased significantly in the NMDA group compared with the control group $(P=0.000)$. As an uncompetitive channel blocker of the NMDA receptor, MK-801 treatment dramatically inhibited NO overproduction triggered by NMDA $(P=0.003$, NMDA versus NMDA + MK-801), suggesting that the increase of NO was triggered by NMDA. The production of NO in the NMDA + HN group was similar to that in the NMDA + MK-801 group and significantly lower than that in the NMDA group $(P=0.002$, NMDA versus NMDA $+\mathrm{HN})$, suggesting that $\mathrm{HN}(1 \mu \mathrm{mol} / \mathrm{L})$ could attenuate NMDA-triggered NO production effectively when the cells were treated $16 \mathrm{~h}$ in advance. NO production in the NMDA + S7A-HN group was significantly higher than that in the control group $(P=0.004$, control versus NMDA $+\mathrm{S} 7 \mathrm{~A}-\mathrm{HN})$. Preincubation with AGA-HNG significantly decreased NO production in

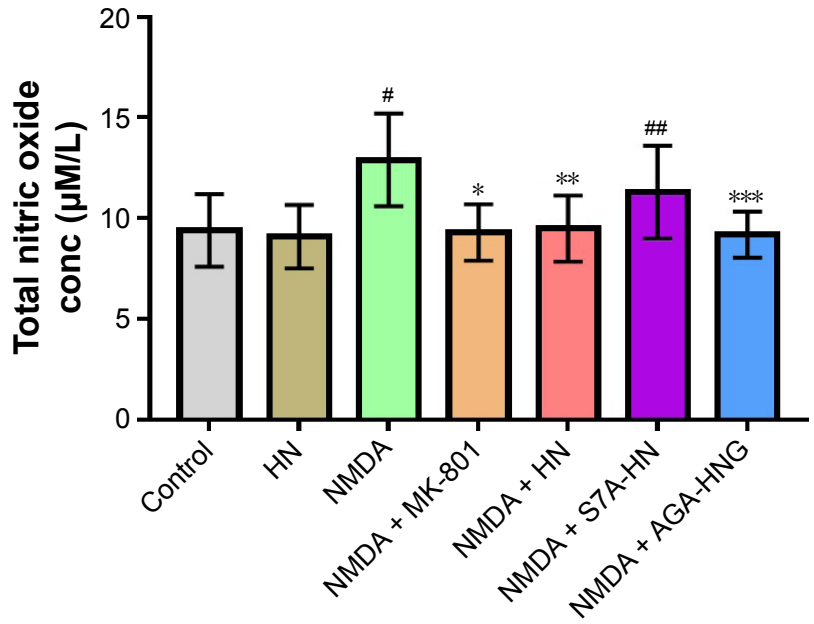

Figure 7 Effect of HN on NMDA-induced nitric oxide production.

Notes: Data are shown as mean \pm SD $(n=5)$. Data were analyzed by I-way ANOVA followed by post hoc Tukey's test for multiple comparisons. ${ }^{\text {\#Control group versus }}$ NMDA group, $P=0.000$; *NMDA versus NMDA + MK-80I, $P=0.003$; **NMDA versus $\mathrm{NMDA}+\mathrm{HN}, P=0.002 ;{ }^{\#}$ control versus $\mathrm{NMDA}+\mathrm{S} 7 \mathrm{~A}-\mathrm{HN}, P=0.004$; ***NMDA versus NMDA + AGA-HNG, $P=0.005$. NMDA: $100 \mu \mathrm{mol} / \mathrm{L} ; \mathrm{MK}-80 \mathrm{I}$ : $10 \mu \mathrm{mol} / \mathrm{L} ; \mathrm{MK}-80 \mathrm{I}: 10 \mu \mathrm{mol} / \mathrm{L} ; \mathrm{HN}, \mathrm{S} 7 \mathrm{~A}-\mathrm{HN}$, and AGA-HNG: I $\mu \mathrm{mol} / \mathrm{L}$ each. NMDA is an excitotoxin that induces the overactivation of NMDA receptor, causing excitotoxicity. MK-80I is a known uncompetitive antagonist of NMDA receptor, which could block the binding of NMDA.

Abbreviations: AGA-HNG, 100x more active form of HN; ANOVA, analysis of variance; conc, concentration; HN, humanin; NMDA, N-methyl-D-aspartate; S7A-HN, inactive form of $\mathrm{HN}$; SD, standard deviation. 
NMDA-treated cells $(P=0.005$, NMDA versus NMDA + AGA-HNG) (Figure 7). Western blot analysis of inducible nitric oxide synthase (iNOS) expression showed that iNOS was dramatically upregulated by NMDA treatment $(P<0.05)$. There was no difference in the iNOS expression levels between the control and the HN-treated cells (Figure S1B).

\section{Discussion}

NMDA receptor-mediated $\mathrm{Ca}^{2+}$ overloading is a pivotal characteristic of glutamate toxicity and is implicated in a variety of pathogeneses, such as stroke, traumatic brain injury, schizophrenia, Parkinson's disease, cerebral ischemia, and neurodegenerative disorders. ${ }^{22,23}$ NMDA receptor antagonists have been explored for many years as therapeutic agents for the treatment of $\mathrm{Ca}^{2+}$ overloading. However, these antagonists often cause severe adverse effects. ${ }^{9,10}$ Not only is $\mathrm{HN}$ a potential versatile neuroprotective agent, but it is also encoded, transcribed, synthesized, and secreted from the occipital lobe of the human brain. Therefore, HN could be a promising candidate for the therapy of excitatory neurotoxicity. In our previous study, we found that $\mathrm{HN}$ effectively rescued cultured rat cortical neurons. ${ }^{18}$ Its mode of action was not due to the blocking of intracellular $\mathrm{Ca}^{2+}$ overloading triggered by NMDA.

Mitochondria and the endoplasmic reticulum can actively sequester $\mathrm{Ca}^{2+}$ in response to high $\mathrm{Ca}^{2+}$ concentration in the cytoplasm, which might be the explanation for the reverting of the high $\mathrm{Ca}^{2+}$ concentration in the cytoplasm. The mitochondrial energy-transducing capacity is essential for the maintenance of neuronal function. NMDA exposure triggered the activation of $\mathrm{Ca}^{2+}$ influx. The mitochondria then actively sequestered $\mathrm{Ca}^{2+}$ to prevent pathologic increases in cytosolic $\left[\mathrm{Ca}^{2+}\right]$. Intramitochondrial $\left[\mathrm{Ca}^{2+}\right]$ increase is a potent signal for the activation of mitochondrial respiration, leading to increased respiration and excessive ROS generation. ${ }^{24}$ Cytochrome $\mathrm{C}$ (Cytc) and other apoptogenic proteins are tethered to the inner mitochondrial membrane by cardiolipin. Excess ROS production in the mitochondria then induced peroxidation and subsequently oxidation of cardiolipin, thereby releasing Cytc and other apoptogenic proteins into the intermitochondrial space. Upon pore formation or alterations in the permeability of the outer mitochondrial membrane, free Cytc and other apoptogenic proteins are released into the cytosol and these subsequently promote the formation of the apoptosome (a complex containing Cytc, caspase 9, and Apaf-1), which activates caspase-related apoptosis. ${ }^{25,26}$ In other words, mitochondrial $\mathrm{Ca}^{2+}$ overload is a critical sensitizing signal in the proapoptotic transition of mitochondria and plays a key role in the regulation of cell death.
To assess the mitochondrial functional situation, 4 functional indexes were tested. The first was mitochondrial SDH activity, an important enzyme in the tricarboxylic acid (TCA) cycle. Neurons are exclusively dependent on mitochondrial ATP generation and have almost no capacity to upregulate energy supply through glycolysis. Therefore, the activity of SDH is the biomarker for the mitochondrial situation. The second is the mitochondrial membrane potential, the foundation of ATP production. On the one hand, the transient mitochondrial membrane hyperpolarization triggered by mitochondrial $\mathrm{Ca}^{2+}$ overload could induce pathological ROS generation and subsequent potential insults. On the other hand, the following depolarization collapse is the pivotal hallmark of irreversible mitochondrial injury and a critical step in the pathway to cell death. The third, namely, the level of ROS, which is one of the by-products of ATP production, is critical. Under normal conditions, $>90 \%$ of oxygen is fully reduced to $\mathrm{H}_{2} \mathrm{O}$ by Cytc oxidase $(\mathrm{CcO})$. Only a small number of electrons "leak" and thereby lead to the partial reduction of $\mathrm{O}_{2}$ to superoxide. Pathophysiologic levels of ROS are triggered by stressful stimuli, such as ischemia, and are produced during the hyperpolarization of $\Delta \Psi \mathrm{m}$. ROS initiates oxidative damage to cellular proteins, lipids, nucleic acids, and polysaccharides throughout the cell. The fourth is the NO level. Electrons escape from the electron transport chain and react with $\mathrm{O}_{2}$ to form superoxide $\left(\mathrm{O}_{2}^{-}\right)$, a potent ROS, or interact with NO to form equally cytotoxic reactive nitrogen species. Among the 4 indexes, SDH can reflect the ability of mitochondria for ATP generation. The mitochondrial membrane potential can reflect the integrity of the ATP machinery. ROS and NO reflect the degree of damage to the ATP machinery and the potential insult to the neurons. ROS and NO both are superoxides, but NO is the major ROS species involved in NMDA receptor-mediated toxicity. ${ }^{4,27}$ The analysis of NO is crucial for the assessment of mitochondrial function.

$\mathrm{HN}$ has been found to prevent stress-induced apoptosis in many cells/tissues. The putative underlying mechanisms include $\mathrm{HN}$ binding to an interleukin (IL)-12-like trimeric membrane receptor, BAX, or IGFBP-3 (a proapoptotic factor). ${ }^{28-30}$ In this research, the $\mathrm{HN}$ concentration used to inhibit NMDA-induced toxicity was much lower than that resulting in HN's protection of the death systems (1-10 $\mathrm{mol} / \mathrm{L})$, as mentioned earlier. This difference suggested that the $\mathrm{HN}$ receptor that mediates the $\mathrm{HN}$-induced protection of rat cortical neurons against NMDA toxicity might be different from the receptor that has been reported in earlier studies. ${ }^{30,31}$ 
The results that HN could attenuate NMDA-induced mitochondrial dysfunction effectively in cultured rat cortical neurons were coincident with the report by Sreekumar et al. ${ }^{32}$ In their research, ${ }^{32}$ Sreekumar et al found that HN protects human retinal pigment epithelial (hRPE) cells from tert-butyl hydroperoxide (tBH)-induced oxidative stress, senescence, and mitochondrial dysfunction. ${ }^{32}$ Exogenous $\mathrm{HN}$ was taken up by the RPE cells and colocalized with the mitochondria, wherein it regulated ROS production, ${ }^{32,33}$ which gives us a clue about the mechanism underlying HN's attenuation of NMDA-induced mitochondrial dysfunction. HN might be directly taken up by the neurons and subsequently translocated into the mitochondria, thereby inhibiting pathological ROS production. ${ }^{32} \mathrm{HN}$ derivatives were reported to inhibit necrotic cell death in neurons by mitigating necrosisassociated decrease in ATP levels. Further, the peptide's direct enhancement of the activity of ATP synthase has also been reported. ${ }^{34}$ Several laboratories have tested the protective effect of $\mathrm{HN}$ on various types of stresses or diseases. Although the specific molecular mechanism of cytotoxicity is unclear for some of these models, eg, $A \beta$ and $3 \times T g-A D$, many have oxidative stress as a common mechanistic denominator, suggesting a specific oxidative insult-related cytoprotective role of HN. ${ }^{35}$ ATP synthase and oxidative insult are closely related to mitochondrial function, which gives a good explanation for HN's versatile cytoprotection, from the broad cell types to different death models.

\section{Conclusion}

We found that NMDA exposure triggered a decrease in cell viability and caused LDH leakage in rat cortical neurons, which could be restored by HN treatment. We further showed that $\mathrm{HN}(1 \mu \mathrm{mol} / \mathrm{L})$ could attenuate NMDA-induced mitochondrial dysfunctions effectively by restoring $\mathrm{SDH}$ activity, blocking the decrease in mitochondrial potential, and neutralizing the excessive ROS and NO produced. The possible underlying mechanism is that $\mathrm{HN}$ is directly absorbed by the neurons and subsequently translocated to the mitochondria; thereafter, it inhibits pathological ROS production.

\section{Acknowledgments}

This study was supported by grants from The National Key Research and Development Program of China (no 2016YFC0100105), the National Science Foundation of China (nos 81628008, 81571641, and 81471652), and an internal grant from the China-Japan Friendship Hospital, Beijing, People's Republic of China (no 2014-3-MS-18).

\section{Disclosure}

The authors report no conflicts of interest in this work.

\section{References}

1. Choi DW. Excitotoxic cell death. J Neurobiol. 1992;23(9):1261-1276.

2. Papouin T, Ladépêche L, Ruel J, et al. Synaptic and extrasynaptic NMDA receptors are gated by different endogenous coagonists. Cell. 2012;150(3):633-646.

3. Zhou X, Hollern D, Liao J, Andrechek E, Wang H. NMDA receptormediated excitotoxicity depends on the coactivation of synaptic and extrasynaptic receptors. Cell Death Dis. 2013;4:e560.

4. Duchen MR. Mitochondria, calcium-dependent neuronal death and neurodegenerative disease. Pflugers Arch. 2012;464(1):111-121.

5. Glancy B, Balaban RS. Role of mitochondrial $\mathrm{Ca}^{2+}$ in the regulation of cellular energetics. Biochemistry. 2012;51(14):2959-2973.

6. Palty R, Hershfinkel M, Sekler I. Molecular identity and functional properties of the mitochondrial $\mathrm{Na}^{+} / \mathrm{Ca}^{2+}$ exchanger. $J$ Biol Chem. 2012;287(38):31650-31657.

7. Rueda CB, Llorente-Folch I, Traba J, et al. Glutamate excitotoxicity and $\mathrm{Ca}^{2+}$ regulation of respiration: Role of the $\mathrm{Ca}^{2+}$ activated mitochondrial transporters (CaMCs). Biochim Biophys Acta. 2016;1857: $1158-1166$.

8. Fraysse B, Nagi SM, Boher B, et al. $\mathrm{Ca}^{2+}$ overload and mitochondrial permeability transition pore activation in living delta-sarcoglycandeficient cardiomyocytes. Am J Physiol Cell Physiol. 2010;299(3): C706-C713.

9. Wu YN, Johnson SW. Memantine selectively blocks extrasynaptic NMDA receptors in rat substantia nigra dopamine neurons. Brain Res. 2015;1603:1-7.

10. Wrighton DC, Baker EJ, Chen PE, Wyllie DJ. $\mathrm{Mg}^{2+}$ and memantine block of rat recombinant NMDA receptors containing chimeric NR2A/2D subunits expressed in Xenopus laevis oocytes. J Physiol. 2008;586(1): 211-225.

11. Hashimoto Y, Niikura T, Ito Y, et al. Detailed characterization of neuroprotection by a rescue factor humanin against various Alzheimer's disease-relevant insults. J Neurosci. 2001;21(23):9235-9245.

12. Hashimoto Y, Ito Y, Niikura T, et al. Mechanisms of neuroprotection by a novel rescue factor humanin from Swedish mutant amyloid precursor protein. Biochem Biophys Res Commun. 2001;283(2):460-468.

13. Tajima H, Niikura T, Hashimoto Y, et al. Evidence for in vivo production of humanin peptide, a neuroprotective factor against Alzheimer's disease-related insults. Neurosci Lett. 2002;324(3):227-231.

14. Tajima H, Kawasumi M, Chiba T, et al. A humanin derivative, S14G-HN, prevents amyloid-beta-induced memory impairment in mice. J Neurosci Res. 2005;79(5):714-723.

15. Mamiya T, Ukai M. [Gly(14)]-humanin improved the learning and memory impairment induced by scopolamine in vivo. Br J Pharmacol. 2001;134(8):1597-1599.

16. Krejcova G, Patocka J, Slaninova J. Effect of humanin analogues on experimentally induced impairment of spatial memory in rats. $J$ Pept Sci. 2004;10(10):636-639.

17. Caricasole A, Bruno V, Cappuccio I, Melchiorri D, Copani A, Nicoletti F. A novel rat gene encoding a humanin-like peptide endowed with broad neuroprotective activity. FASEB J. 2002;16(10): 1331-1333.

18. Cui AL, Li JZ, Feng ZB, et al. Humanin rescues cultured rat cortical neurons from NMDA-induced toxicity not by NMDA receptor. ScientificWorldJournal. 2014;2014:341529.

19. Cebere A, Liljequist S. Ethanol differentially inhibits homoquinolinic acid- and NMDA-induced neurotoxicity in primary cultures of cerebellar granule cells. Neurochem Res. 2003;28(8): 1193-1199.

20. Koh JY, Choi DW. Vulnerability of cultured cortical neurons to damage by excitotoxins: differential susceptibility of neurons containing NADPH-diaphorase. J Neurosci. 1988;8(6):2153-2163. 
21. Li R, Guo M, Zhang G, Xu X, Li Q. Neuroprotection of nicotiflorin in permanent focal cerebral ischemia and in neuronal cultures. Biol Pharm Bull. 2006;29(9):1868-1872.

22. Chen Z, Zhou Q, Zhang M, Wang H, Yun W, Zhou X. Co-activation of synaptic and extrasynaptic NMDA receptors by neuronal insults determines cell death in acute brain slice. Neurochem Int. 2014;78: 28-34.

23. Toglia P, Cheung KH, Mak DD, Ullah G. Impaired mitochondrial function due to familial Alzheimer's disease-causing presenilins mutants via $\mathrm{Ca}\left({ }^{2+}\right)$ disruptions. Cell Calcium. 2016;59(5):240-250.

24. Takeuchi A, Kim B, Matsuoka S. The destiny of $\mathrm{Ca}\left({ }^{2+}\right)$ released by mitochondria. J Physiol Sci. 2015;65(1):11-24.

25. Sanderson TH, Reynolds CA, Kumar R, Przyklenk K, Hüttemann M. Molecular mechanisms of ischemia-reperfusion injury in brain: pivotal role of the mitochondrial membrane potential in reactive oxygen species generation. Mol Neurobiol. 2013;47(1):9-23.

26. Corona JC, Duchen MR. Impaired mitochondrial homeostasis and neurodegeneration: towards new therapeutic targets. J Bioenerg Biomembr. 2015;47(1-2):89-99.

27. Drechsel DA, Estévez AG, Barbeito L, Beckman JS. Nitric oxidemediated oxidative damage and the progressive demise of motor neurons in ALS. Neurotox Res. 2012;22(4):251-264.

28. Guo B, Zhai D, Cabezas E, et al. Humanin peptide suppresses apoptosis by interfering with Bax activation. Nature. 2003;423(6938): $456-461$.
29. Ikonen M, Liu B, Hashimoto $Y$, et al. Interaction between the Alzheimer's survival peptide humanin and insulin-like growth factorbinding protein 3 regulates cell survival and apoptosis. Proc Natl Acad Sci U S A. 2003;100(22):13042-13047.

30. Ying G, Iribarren P, Zhou Y, et al. Humanin, a newly identified neuroprotective factor, uses the $\mathrm{G}$ protein-coupled formylpeptide receptor-like-1 as a functional receptor. J Immunol. 2004;172(11): 7078-7085.

31. Hashimoto Y, Kurita M, Aiso S, Nishimoto I, Matsuoka M. Humanin inhibits neuronal cell death by interacting with a cytokine receptor complex or complexes involving CNTF receptor alpha/WSX-1/gp130. Mol Biol Cell. 2009;20(12):2864-2873.

32. Sreekumar PG, Ishikawa K, Spee C, et al. The mitochondrial-derived peptide humanin protects RPE cells from oxidative stress, senescence, and mitochondrial dysfunction. Invest Ophthalmol Vis Sci. 2016;57(3): 1238-1253

33. Paharkova V, Alvarez G, Nakamura H, Cohen P, Lee KW. Rat humanin is encoded and translated in mitochondria and is localized to the mitochondrial compartment where it regulates ROS production. Mol Cell Endocrinol. 2015;413:96-100.

34. Cohen A, Lerner-Yardeni J, Meridor D, Kasher R, Nathan I, Parola AH. Humanin derivatives inhibit necrotic cell death in neurons. Mol Med. 2015;21:505-514.

35. Lee C, Yen K, Cohen P. Humanin: a harbinger of mitochondrial-derived peptides. Trends Endocrinol Metab. 2013;24(5):222-228. 


\section{Supplementary material}

A

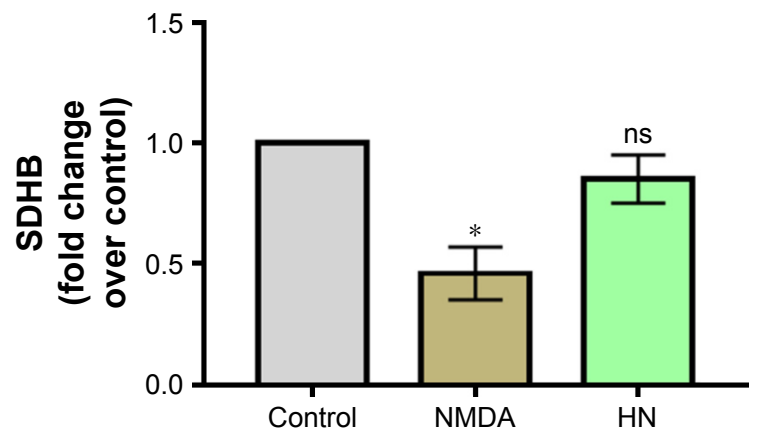

B

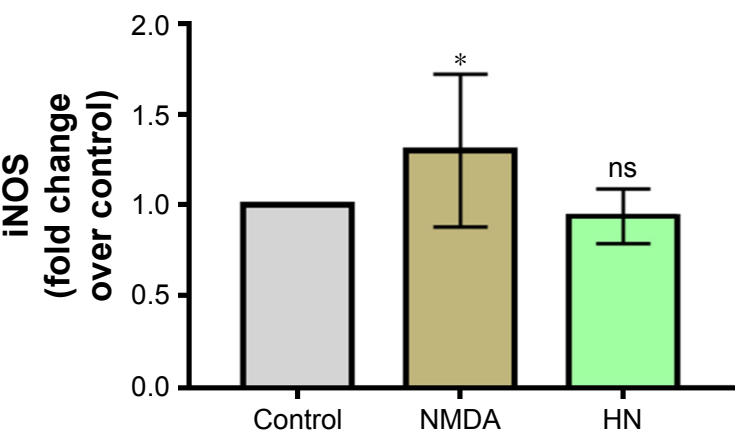

Figure SI The effect of HN treatment on the expression of mitochondrial (A) succinate dehydrogenase and (B) nitric oxide synthase.

Notes: The cells were treated with either NMDA ( $100 \mu \mathrm{mol} / \mathrm{L})$ or NMDA ( $100 \mu \mathrm{mol} / \mathrm{L})+\mathrm{HN}(\mathrm{I} \mu \mathrm{mol} / \mathrm{L})$. Mitochondrial proteins were extracted and subjected to Western blot analysis with anti-SDHB and anti-iNOS antibodies. Beta-actin was used as the loading control. SDHB and iNOS expressions were quantified using Image I.3.8 and expressed as the fold change relative to the control. The experiments were repeated 3 times, and the intensity data are presented as mean $\pm S D$ ( $=3$ ). $* P<0.05$, compared with the control.

Abbreviations: HN, humanin; iNOS, inducible nitric oxide synthase; NMDA, N-methyl-D-aspartate; ns, nonsignificant; SD, standard deviation; SDHB, mitochondrial succinate dehydrogenase subunit $B$.

\section{Publish your work in this journal}

Drug Design, Development and Therapy is an international, peerreviewed open-access journal that spans the spectrum of drug design and development through to clinical applications. Clinical outcomes, patient safety, and programs for the development and effective, safe, and sustained use of medicines are the features of the journal, which has also been accepted for indexing on PubMed Central. The manuscript management system is completely online and includes a very quick and fair peer-review system, which is all easy to use. Visit http://www.dovepress.com/testimonials.php to read real quotes from published authors. 